RIZZO, A.A.N.; CHAVES, F.C.M.; LAURA, V.A.; GOTO, R. Avaliação de métodos de enxertia e porta-enxertos para melão rendilhado. Horticultura Brasileira, Brasília, v.22, n.4, p.808-810, out-dez 2004.

\title{
Avaliação de métodos de enxertia e porta-enxertos para melão rendilhado
}

\author{
Adriana A. do N. Rizzo' ${ }^{1}$; Francisco C.M. Chaves²; Valdemir Antonio Laura ${ }^{3}$; Rumy Goto ${ }^{4}$ \\ ${ }^{1}$ UNESP, Depto. Produção Vegetal, Via de Acesso Prof. Paulo Donato Castellane, s/n, 14884-900 Jaboticabal-SP; E-mail:

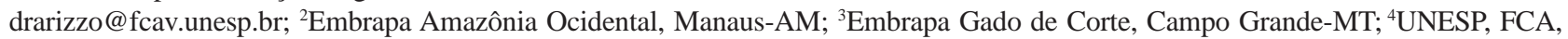 \\ Botucatu-SP.
}

\begin{abstract}
RESUMO
Foram avaliados três métodos de enxertia e cinco porta-enxertos para melão rendilhado 'Bônus $n^{\circ} 2$ ' em condições de ambiente protegido na UNESP em Botucatu (SP). Utilizaram-se 15 tratamentos distribuídos em blocos ao acaso com 3 repetições. A taxa de sobrevivência após as enxertias, peso médio, dimensões e teor de sólidos solúveis totais dos frutos produzidos em plantas enxertadas foram avaliadas. Dentre os métodos de enxertia e porta-enxertos avaliados, os melhores resultados para melão rendilhado 'Bônus $\mathrm{n}^{\circ}$ 2' foram obtidos utilizando-se os métodos fenda cheia e perfuração lateral combinado ao porta-enxerto 'Shelper'.
\end{abstract}

Palavras-chave: Cucumis melo var. reticulatus, ambiente protegido, qualidade de frutos.

\begin{abstract}
Evaluation of grafting types and rootstocks for muskmelon

Three grafting types and five rootstocks for 'Bônus $n^{\circ} 2$ ' muskmelon, as well as the fruit quality of grafted plants, were evaluated in a greenhouse, in Botucatu, São Paulo State, Brazil. The 15 treatments were distributed in randomized blocks with 3 replications. The survival rate, mean weight, longitudinal and transversal diameter of fruits and percentage of total soluble solids were evaluated in grafted plants. The best results for 'Bônus $n^{\circ} 2^{\text {' }}$ were obtained using grafting by cleft graft and lateral drilling in combination with 'Shelper' as rootstocks.
\end{abstract}

Keywords: Cucumis melo var. reticulatus, greenhouse, fruit quality.

\section{(Recebido para publicação em 3 de abril de 2003 e aceito em 2 de setembro de 2004)}

$\mathrm{O}$ melão (Cucumis melo L.) é uma hortaliça que teve seu cultivo comercial iniciado no sudeste do Brasil na década de 60, e desde então vem ganhando importância econômica. De acordo com Robinson e Walters (1997), a espécie Cucumis melo está classificada em 6 grupos botânicos, de acordo com as características do fruto e de consumo. Considerando-se estas características, o melão rendilhado ( $C$. melo var. reticulatus Naud.) pertence ao grupo Cantalupensis. Estes melões caracterizam-se por apresentar a superfície do fruto rendilhada, formato redondo a ovalado, pesar de 1 a $3 \mathrm{~kg}$, ter aroma marcante, ser bastante doces (sólidos solúveis ao redor de $10^{\circ}$ Brix) e ter polpa com cor que varia entre verde-claro e salmão. O melão rendilhado possui ciclo vegetativo curto, que é favorecido quando há elevada irradiância, altas temperaturas, baixa umidade relativa, boas condições de irrigação e não ocorrência de geadas, consistindo em boa opção para os olericultores para cultivo em casa de vegetação (Rizzo, 1999).

O cultivo em ambiente protegido possibilita semear o melão em várias épocas, proporcionando várias colhei- tas por ano, além de proporcionar altos níveis de produtividade (1800-3000 frutos/1000 $\mathrm{m}^{2}$ de casa de vegetação) (Brandão Filho e Vasconcellos, 1998).

Devido ao aumento de áreas cultivadas com meloeiro em condições de ambiente protegido, muitas vezes sem orientação técnica adequada, acentuou-se a ocorrência de problemas no cultivo, ocasionando o aumento da incidência de doenças, nematóides e salinização do solo, por vezes limitando o cultivo. Estes problemas geraram a necessidade de busca de alternativas para continuar o cultivo neste sistema de produção. Uma das alternativas encontradas foi a utilização de enxertia, pelo uso de porta-enxertos tolerantes ou resistentes a patógenos e condições adversas de ambiente.

Oda (1995) relata que a primeira referência de utilização de plantas enxertadas em plantios comerciais data de 1920, no Japão e Coréia, quando realizou-se enxertia para melancia. Desde então, a área de produção de hortaliças frutos utilizando esta técnica tem aumentado consideravelmente, principalmente em ambiente protegido. Em 1995, segundo o mesmo autor, no Japão utilizavam-se plantas enxertadas em $93 \%$ da área cultivada de melancia, $72 \%$ de pepino, $50 \%$ de berinjela, $32 \%$ de tomate e em $30 \%$ de todos os tipos de melões cultivados.

A enxertia envolve a união de partes de plantas distintas que pela regeneração de tecidos resultante da união física destas, passam a se desenvolver como uma única planta (Janick, 1966). O sucesso da enxertia depende de alguns fatores que promovam a formação de calos. Dentre estes estão a limpeza e rapidez no corte dos tecidos, evitando ao máximo a perda de umidade nos tecidos, e as condições ambientais que estão envolvidas após a enxertia, devendo-se sempre manter o ambiente quente e úmido (Oda et al., 1993).

A enxertia sobre porta-enxertos apropriados oferece uma série de vantagens em relação ao cultivo normal, como redução de doenças causadas por fungos de solo, tais como Fusarium sp., Phytophthora melonis, aumento da tolerância à baixas temperaturas (Oda, 1995), à salinidade e excesso de umidade do solo. A enxertia colabora também para o melhor aproveitamento de água e nutrientes, para o aumento do vigor da planta e prolongamento do período de colheita, 
pois na maioria das vezes o porta-enxerto possui sistema radicular mais vigoroso que o da planta enxertada.

Como exemplo de porta-enxertos utilizados para melão em cultivo protegido, tem-se 'Kurodane' (Cucurbita ficifolia), 'Oi', 'Enken n'2' e 'Bernet (Cucumis melo), 'Lion' (Benincasa hispida) e 'Uryu' (Cucurbita spp.).

Em enxertos de pepino em abóboras a taxa de sobrevivência correlacionou-se inversamente com as diferenças nos diâmetro dos hipocótilos do enxerto e porta-enxerto, ou seja, os conjuntos enxerto/porta-enxerto que tiveram maior índice de sobrevivência foram os mais próximos quanto a distribuição e número de feixes vasculares (Oda et al., 1993)

Alexandre et al. (1997) estudaram em ambiente protegido o efeito dos métodos de enxertia fenda terminal e encostia, sobre três porta-enxertos, tendo como enxerto o melão 'Gália'. A combinação mais produtiva foi a 'Gália'/'RS-841'/Encostia (6,8 kg/planta), seguida por 'Gália'/'Tetsukabuto'/ encostia (6,1 kg/planta) e por 'Gália'/ RS-841/Fenda cheia (5,0 kg/planta). Para as características proporção polpa/ sementes, acidez (pH) e sólidos solúveis totais $\left({ }^{\circ}\right.$ Brix), não houve diferenças significativas entre as plantas enxertadas e o controle.

Estes autores, nas mesmas condições do experimento anterior, avaliaram a influência dos métodos de enxertia utilizados na porcentagem de pegamento, afinidade copa/porta-enxerto e uniformidade de crescimento. O melão 'Gália' foi utilizado como copa nos porta-enxertos 'Tetsukabuto', 'Chila' e melão 'Jador', em três métodos de enxertia (fenda terminal, encostia e perfuração lateral). Observaram $92,0 \%$ de pegamento das enxertias por fenda terminal, $87,0 \%$ para a perfuração lateral e 71,0\% para a encostia. Para a afinidade copa/porta-enxerto, o método fenda terminal proporcionou a melhor afinidade, seguido por encostia e perfuração lateral.

Devido a inexistência de dados sobre os materiais mais utilizados pelos produtores brasileiros, o presente trabalho teve como objetivos avaliar os métodos de enxertia e os porta-enxertos

Tabela 1. Porcentagem de pegamento de enxertias de melão rendilhado 'Bônus no 2 ', em função dos métodos de enxertia e porta-enxertos. Botucatu, UNESP, 1999.

\begin{tabular}{|c|c|c|c|c|c|}
\hline \multirow{2}{*}{$\begin{array}{l}\text { Métodos de } \\
\text { enxertia }\end{array}$} & \multicolumn{5}{|c|}{ Porta-enxertos } \\
\hline & Shelper & Maxixe & Bucha & $\begin{array}{c}\text { Híbrido base } \\
\text { Takii }\end{array}$ & Bônus $n^{\circ} 2$ \\
\hline Encostia & $79,17 \mathrm{AB}^{*} \mathrm{~b}^{*}$ & $68,75 \mathrm{~B}$ ab & $94,33 \mathrm{~A} \mathrm{a}$ & $62,50 \mathrm{~B} \mathrm{~b}$ & $93,73 \mathrm{~A} a$ \\
\hline Fenda cheia & $100,00 \mathrm{~A} \mathrm{a}$ & $70,83 \mathrm{~B} \mathrm{a}$ & $83,33 \mathrm{AB}$ ab & $83,33 \mathrm{AB}$ a & $89,57 \mathrm{AB}$ a \\
\hline Perf. lateral & $79,17 \mathrm{~A} \mathrm{~b}$ & $52,08 \mathrm{~B} \mathrm{~b}$ & $66,66 \mathrm{AB} b$ & $62,50 \mathrm{AB} b$ & $81,25 \mathrm{~A} a$ \\
\hline
\end{tabular}

*Médias seguidas de mesma letra não diferem entre si pelo teste de Tukey a 5\% de probabilidade. Letras maiúsculas comparam-se nas linhas e minúsculas nas colunas.

(PE) que possam vir a ser utilizados para melão rendilhado, e o desempenho das plantas enxertadas com relação a produção e qualidade de frutos.

\section{MATERIAL E MÉTODOS}

O ensaio foi conduzido em condições de ambiente protegido, em área da UNESP em Botucatu (SP), durante os meses de maio a setembro de 1999. Utilizou-se casa de vegetação tipo arco, coberto com filme de polietileno de baixa densidade, transparente de 100 micra de espessura com as dimensões de 7,0x30,0m, apresentando um pé direito de $3,0 \mathrm{~m}$.

Avaliou-se o pegamento dos enxertos na fase de mudas, utilizando-se o delineamento inteiramente casualizado em esquema fatorial $3^{\prime}$ '5, com 15 tratamentos resultantes das combinações entre os três métodos de enxertia: encostia (ENC), fenda cheia (FC) e perfuração lateral (PER) e cinco porta-enxertos (PE) ('Shelper', Maxixe, Bucha, Híbrido Base Takii e 'Bônus n 2' - testemunha) com 3 repetições, tendo a cv. Bônus $n^{\circ} 2$ como copa. Estes portaenxetos foram escolhidos por serem genótipos disponíveis comercialmente e de fácil aquisição pelos produtores nacionais.

A semeadura dos porta enxertos (PE) e enxerto (E) (Bônus $\mathrm{n}^{\circ}$ 2) foi realizada nos dias 08 e 12/04/1999, respectivamente. As mudas foram produzidas em bandejas de poliestireno expandido com 128 células

As enxertias sobre os PE e em 'Bônus $n^{\circ} 2$ ' foram realizadas nos dias 20 e 27/04/1999, respectivamente, quando porta-enxerto e copa apresentavam a primeira folha verdadeira. As plantas enxertadas foram colocadas em câmara úmida para manutenção da umidade de $90 \%$ e temperatura média UR e $30^{\circ} \mathrm{C}$, permanecendo por 7 dias e sendo gradativamente adaptadas para retirada destas condições e para o transplante. A avaliação do pegamento das enxertias foi realizada 20 dias após a enxertia.

Para a avaliação da produção das plantas enxertadas, em casa de vegetação, o transplantio para a casa de vegetação ocorreu em 18/05/99, aproximadamente um mês após as enxertias. Adotou-se o delineamento em blocos ao acaso, com 15 tratamentos e quatro repetições. As parcelas foram constituídas por seis plantas espaçadas $1,0 \times 0,5 \mathrm{~m}$, conduzidas com uma haste principal, tutoradas por fios de ráfia até $2,0 \mathrm{~m}$ de altura. Foram avaliados: massa fresca (g), diâmetro transversal e longitudinal médio $(\mathrm{cm})$ e teor total de sólidos solúveis ( ${ }^{\circ}$ Brix) dos frutos.

\section{RESULTADOS E DISCUSSÃO}

Foram observadas interações entre os métodos de enxertia e as combinações com os porta-enxertos (Tabela 1). As combinações que utilizaram 'Shelper' como porta-enxerto apresentaram maior valor de porcentagem de pegamento quando as enxertias foram feitas pelos métodos fenda cheia e perfuração lateral. Contudo, não foi diferente estatisticamente dos genótipos Bucha e híbrido base Takii.

A maior porcentagem de pegamento quando as enxertias foram realizadas por encostia foi obtida com o genótipo $\mathrm{Bu}$ cha, porém, não foi diferente estatisticamente do genótipo Shelper.

O tratamento shelper/fenda cheia atingiu o maior valor de massa de fru- 
tos, diferindo estatisticamente apenas dos tratamentos envolvendo maxixe/ encostia, bucha/encostia, híbrido base Takii/encostia e bucha/fenda cheia (Tabela 2).

Os maiores valores de diâmetro médio longitudinal dos frutos foram obtidos quando se utilizaram as combinações 'Shelper' fenda cheia e perfuração lateral, diferindo apenas de bucha/fenda cheia e hib. Base Takii/encostia (Tabela 2).

Já para ${ }^{\circ}$ Brix (Tabela 2), o maior valor foi atingido pelos frutos oriundos da combinação fenda cheia e Maxixe, que diferiu estatisticamente dos frutos encontrados nas combinações maxixe/ encostia, bucha/encostia, híbrido base Takii/encostia, 'Bônus n²'/encostia, bucha/fenda cheia, híbrido base Takii / fenda cheia e híbrido base Takii/ perfuração lateral.

Para diâmetro médio transversal dos frutos, não foram detectadas diferenças significativas entre os tratamentos, com valores médios de $8,5 \mathrm{~cm}$.

Dentre os métodos de enxertia avaliados, sugere-se a utilização do método fenda cheia, por ter sido inferior apenas na combinação com bucha como porta-enxerto, e como porta-enxerto os melhores desempenhos foram observados quando se utilizou 'Shelper'.

Além de ter apresentado bons índices de pegamento, 'Shelper' proporcionou manutenção de características de frutos desejáveis aos consumidores, como boa massa e dimensões de frutos, assim como razoável índice de sólidos solúveis totais.

Tabela 2. Médias de massa, diâmetros longitudinal e transversal e sólidos solúveis totais em frutos de melão rendilhado 'Bônus n'2', em função das combinações dos métodos de enxertia e porta-enxertos. Botucatu, UNESP, 1999.

\begin{tabular}{lccc}
\hline & \multicolumn{3}{c}{ Características } \\
\cline { 2 - 4 } Tratamentos & $\begin{array}{c}\text { Massa de } \\
\text { frutos (kg) }\end{array}$ & $\begin{array}{c}\text { Diâmetro } \\
\text { longitudinal } \\
\text { de frutos } \\
\text { (cm) }\end{array}$ & $\begin{array}{c}\text { Sólidos } \\
\text { solúveis } \\
\text { totais ('Brix) }\end{array}$ \\
\hline Shelper/Encostia & $498,37 \mathrm{abc}^{*}$ & $9,12 \mathrm{ab}$ & $8,53 \mathrm{abc}$ \\
Maxixe/Encostia & $266,80 \mathrm{~cd}$ & $7,79 \mathrm{abc}$ & $6,50 \mathrm{c}$ \\
Bucha/Encostia & $280,83 \mathrm{bcd}$ & $7,62 \mathrm{abc}$ & $7,10 \mathrm{bc}$ \\
Hib. para melão base Takii /Encostia & $279,67 \mathrm{bcd}$ & $7,20 \mathrm{bc}$ & $6,80 \mathrm{bc}$ \\
Bônus n 2/Encostia & $343,83 \mathrm{abcd}$ & $8,06 \mathrm{abc}$ & $7,57 \mathrm{bc}$ \\
Shelper/Fenda Cheia & $561,13 \mathrm{a}$ & $9,35 \mathrm{a}$ & $8,83 \mathrm{abc}$ \\
Maxixe/Fenda Cheia & $459,80 \mathrm{abc}$ & $8,53 \mathrm{abc}$ & $10,63 \mathrm{a}$ \\
Bucha/Fenda Cheia & $191,83 \mathrm{~d}$ & $7,01 \mathrm{c}$ & $8,63 \mathrm{bc}$ \\
Hib. para melão base Takii /Fenda Cheia & $318,03 \mathrm{abcd}$ & $8,05 \mathrm{abc}$ & $7,27 \mathrm{bc}$ \\
Bônus n 2/Fenda Cheia & $419,70 \mathrm{abcd}$ & $8,56 \mathrm{abc}$ & $8,03 \mathrm{abc}$ \\
Shelper/Perf. Lateral & $519,87 \mathrm{ab}$ & $9,42 \mathrm{a}$ & $8,97 \mathrm{abc}$ \\
Maxixe/Perf. Lateral & $385,23 \mathrm{abcd}$ & $8,09 \mathrm{abc}$ & $9,50 \mathrm{ab}$ \\
Bucha/Perf. Lateral & $379,68 \mathrm{abcd}$ & $8,24 \mathrm{abc}$ & $8,00 \mathrm{abc}$ \\
Hib. para melão base Takii /Perf. Lateral & $335,77 \mathrm{abcd}$ & $7,90 \mathrm{abc}$ & $6,97 \mathrm{bc}$ \\
Bônus n 2/Perf. Lateral & $446,03 \mathrm{abc}$ & $8,55 \mathrm{abc}$ & $7,87 \mathrm{abc}$ \\
\hline CV (\%) & 21,70 & 8,04 & 11,89 \\
\hline
\end{tabular}

*Médias nas colunas seguidas de mesma letra não diferem entre si pelo teste de Tukey a $5 \%$ de probabilidade.

\section{LITERATURA CITADA}

ALEXANDRE, B.M., DIAS, J.S., MARREIROS, A. Influência do tipo e do porta-enxerto, na produtividade e qualidade do melão "Gália" em estufa, no Algarve. In: II Congresso Iberoamericano e III Congresso Ibérico de Ciências Hortícolas, n.16, 1997, Vilamoura. Actas... Vilamoura: Confederación Latino Americana de Horticultura, 1997, p.147-52.

BRANDÃO FILHO, J.U.T, VASCONCELOS, M.A.S. A cultura do meloeiro. In: GOTO, R., TIVELLI, S.W. Produção de hortaliças em ambiente protegido: condições subtropicais. São Paulo: Fundação Editora da UNESP, 1998, p.161194.
JANICK, J. A ciência da horticultura. Rio de Janeiro: Freitas Bastos, 1966, p.224-329.

ODA, M., TSUJI, K., SASAKI, H. Effect of hypocotyl morphology on survival rate and grow of cucumbers seedlings grafted on Cucurbita spp. Jpn. A.R.Q., v.26, n.4, p.259-263, 1993.

ODA, M. New grafting methods for fruit-bearing vegetables in Japan. Jpn. A.R.Q., v.29, n.3, p.187194, 1995.

RIZZO, A.A.N. Avaliação de caracteres agronômicos e qualitativos de cinco cultivares de melão rendilhado (Cucumis melo var. reticulatus Naud.) $e$ da heterose de seus híbridos $F_{l}$. Jaboticabal, 1999. 61 p. (Tese mestrado) UNESPaulista, Jaboticabal, 1999.

ROBINSON, R.W., DECKER-WALTERS, D.S. Cucurbits. CAB Inernational, Cambridge, 1997, 226 p. 